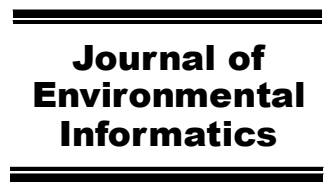

www.iseis.org/jei

\title{
Theory of Willingness to Sell to Valuate Ecosystem Services in the Contingent Valuation Method
}

\author{
Y. Chang ${ }^{1 *}$ and K. Yoshino ${ }^{2}$ \\ ${ }^{1}$ Graduate School of Life and Environmental Sciences, University of Tsukuba, Tsukuba, Ibaraki Prefecture 305-8571, Japan \\ ${ }^{2}$ Department of System and Information Engineering, University of Tsukuba, Tsukuba, Ibaraki Prefecture 305-8571, Japan
}

Received 12 April 2016; revised 18 January 2017; accepted 26 January 2017; published online 27 March 2017

\begin{abstract}
Willingness to Pay (WTP) and Willingness to Accept (WTA) is the mainstream of the contingent valuation method (CVM) and especially the willingness to pay techniques is widely used in valuating public goods and ecosystem services in many areas in the world. The main technique of WTP in CVM is to achieve the maximum value that public would like to pay for some ecosystem services; unfortunately, it is always accompanied by a psychological phenomenon as free rider, since actually, everyone can enjoy the public goods equally no matter how much they paid, which is also the definition and feature of the public goods. While, although recent advances have considerably reduced the biases and shortcomings of CVM such as embedding effect and hypothetical bias. Researchers still faced with a need for a new method, which is fundamentally interfered with less psychological factors. This paper presents a first attempt to build the theory of Willingness to Sell (WTS) to quantify the economic value of the ecosystem services on the basis of the combination of existing environmental science and economics. WTS is a method to achieve a reasonable equilibrium price through the public judgment on the value of public goods or ecosystem services rather than the production costs of the supplier. The theoretical construction, mathematical modeling, implementation of the process, and survey method and question designs of WTS have been discussed and presented in this research. We believe that a more objective and reliable economic value of ecosystem service could be drawn through the combination of the new method and existing WTP and WTA skills, and the validity of CVM method research will also be greatly improved.
\end{abstract}

Keywords: Contingent valuation method, willingness to sell, willingness to pay, willingness to accept, willingness to depreciate

\section{Introduction}

Ecosystem services are critical to the functioning of the Earth's life-support system and contribute to human welfare (d'Arge et al., 1997). Since environmental strategy assessment is becoming increasingly important in many countries and areas, the economic value of ecosystem services, public services, public goods, environmental resources and tourism resources is becoming a key when evaluating whole planning projects. The Contingent Valuation Method (CVM) has been the main methodology used to appraise non-market goods and services in the past 50 years, since the CVM was derived from survey research techniques (Mitchell and Carson, 2013), researchers designed a series of questions to establish the circumstances under which maximum value might be gained through its use in survey research (Rea and Parker, 2012). The CVM lacks precision and cannot be achieved by following rigid rules (Mitchell and Carson, 2013). This is because its use depends on specific case

\footnotetext{
* Corresponding author. Tel.: +86 59186398509 ; fax: +86 59183776849.

E-mail address: Yaxuanchang@yahoo.co.jp (Y. Chang).
}

ISSN: 1726-2135 print/1684-8799 online

(C) 2017 ISEIS All rights reserved. doi:10.3808/jei.201700362 details (Yin, 2013), which is also the reason why it is called a contingent method (Portney, 1994). The essence of CVM research is about study design and careful implementation (Carson et al., 2001). If each aspect of the survey process is well conducted, the results will contain higher precision, accuracy, and credibility (Fowler, 2008). In CVM research, the overall design and strategy must be set into its important contextual position to explore every detail of the valuation program (Hakim, 1987).

In order to assess the quality of each case study and make them more reliable and replicable (Yin and Heald, 1975), researchers use techniques and guidance through applying different case studies to test the heuristic identification of new variables and hypotheses (George and Bennett, 2005). All the techniques employed in conducting survey questions can be divided into willingness to pay (WTP) and willingness to accept (WTA) (Shogren et al., 1994). While both the techniques of WTP and WTA have been considered existing several problems, although recent advances have considerably reduced the biases and shortcomings of CVM, WTP is still accompanied by a psychological phenomenon as free rider and there is still a certain gap between the WTP value and the executable market price. Although WTP is more widely used in field survey than WTA, while the financial contribution based on WTP questions is sometime 
uncertain (Yoshino, 2010). This research provides a new solution for valuating ecosystem services more objectively using CVM method. In this research, the theory of a new technical component, 'willingness to sell' (WTS) is built up to valuate the ecosystem services, by asking respondents how much can the effect of eco-service be sold or worth on the viewpoint of a thirdparty, and the respondents will give out a value on the basis of their common sense of the real market. The conducting process and survey techniques of WTS were designed, and it was compared with the existing techniques of WTP and WTA through the most basic questions in the preliminary test of the field survey in this research.

\section{Methods}

We used Comprehensive Comparative Method (CCM) to conduct a comparative study on the definition, classification and principle of WTS, WTP and WTA. Microanalysis Method (MM) and Summarizing Method (SM) are combined to exploring a number of CVM research cases; we culled research papers for economic valuation attempts on different types of ecosystem services such as urban planning and tourism resources and also collected publication that originally described the original method and history. Through the process of classifying and summarizing, we then developed WTS theory on the basis of the combination of environmental science and economics.

\section{Theory of Willingness to Sell}

\subsection{Consumer Surplus and Producer Surplus}

In the theory of WTP, it requires the maximum amount of money that can be paid on the basis of a certain amount of utility. For WTS, it is on the opposite side of WTP, it requires an equilibrium price on the basis of a certain amount of utility. As it shown in Figure 1, if we assume the consumers get the same effect when facing the same ecosystem services, WTP is trying to conjecture the upper limit (Line a) of consumer surplus area and WTS is trying to conjecture the lower limit (Line b) of consumer surplus area. Thus, WTP is usually conducted by asking the respondents how much can be paid for some ecosystem services; And WTS can be conducted by asking the public what may be the reasonable price for some ecosystem services, then, the government or the organization may get some references of deciding how to act the role as a producer of the ecosystem services.

As an ordinary commodity, the production cost is knowable in the general market in the economics, while, for the environment or ecosystem services (see Figure 2), many times it does not depend on the actual production costs of the manufacturer, but how much money to provide how much implementation to get (Process a). Thus, there may exist two contrary methods theoretically to measure the quantity of economic value of ecosystem services, one is to ask how much can be provided for a certain amount of services (Process b), and the other is that for a certain amount of services, it may be implemented by how much money (Process c). The first method is closed to the concept of buyer and the second method is closed to the producer; the first method is the Willingness to Pay techniques as everyone knows and the second method is organized as Willingness to Sell techniques in this research, it is, how much may an implementation of some ecosystem services worth or how much can a public goods be sold. And in this paper, the second method will be presented to "how much can be sold" techniques as one of the basic survey techniques in WTS.

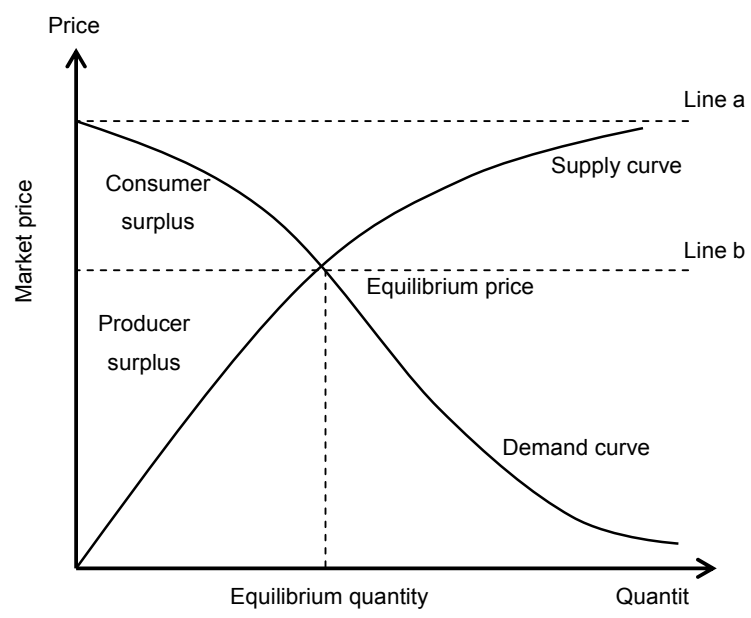

Figure 1. Consumer surplus and producer surplus model.

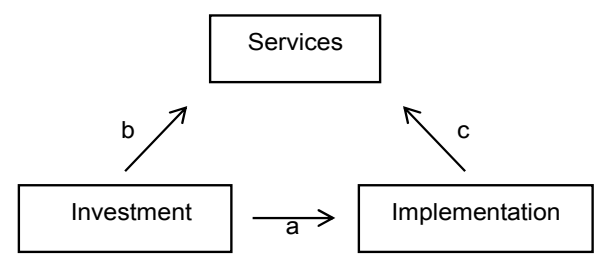

Figure 2. Relationships between investment and implementation.

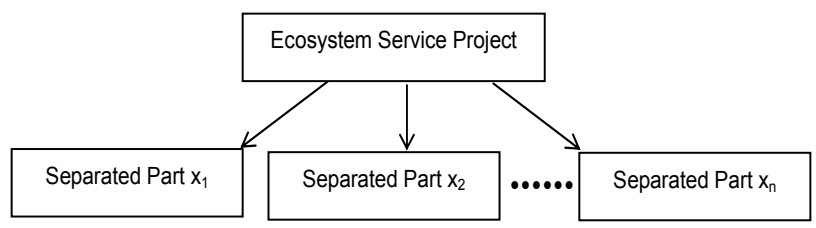

Figure 3. Ecosystem service separating process.

\subsection{Process Design and Computational Method}

Since valuations of ecosystems should focus on specific relationships, as each relationship may require a different valuation approach and the total ecosystem value of can be a summation of these different services (Dewsbury et al., 2016); and a whole project is difficult for public to valuate exactly, the process needs to be separated into specific parts. Figure 3 shows the separating process of the whole ecosystem service project. Before the implementation of the assessment process, the project should be reasonably divided into more specific and smaller items. For example, a park planning may be divided into green vegetation, artificial landscape, leisure facilities and in- 
frastructure. Each separated part should be valuated independently and then each part will be added up and finally the WTS value of the whole project $M$ is concluded out as the formula shows below. WTS value (Possible Selling Price) is expressed as $p=\left(p_{1}, p_{2}, \ldots, p_{n}\right)$.

$$
\begin{aligned}
& p_{1} x_{1}+p_{2} x_{2}+\ldots+p_{n} x_{n}=\sum_{j=1}^{n} p_{j} x_{j} \\
& \sum_{j=1}^{n} p_{j} x_{j}=M
\end{aligned}
$$

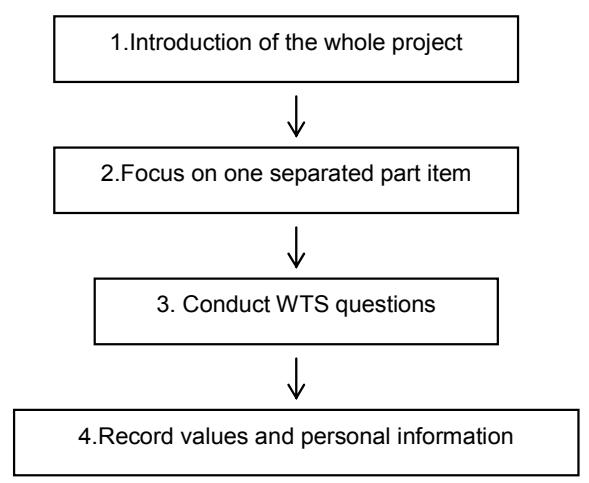

Figure 4. Outline of the field survey process.

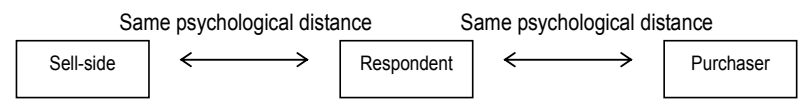

Figure 5. Principles of description and explanation method.

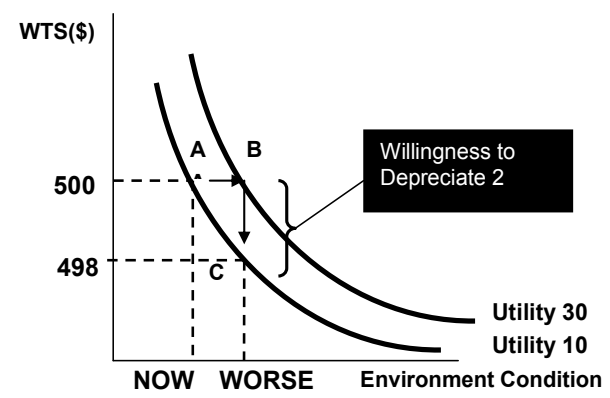

Figure 6. Indifference curve of utility in willingness to sell.

\subsection{WTS Survey Techniques and Question Design}

Figure 4 shows the outline of the WTS field survey process, the introduction of the whole ecosystem service project should be described at first and explanation with attached image data is considered an effective description method. Secondly, guide respondent's focus on the assessment of each item, which has been split before going to field survey. Then, WTS questions will be asked and finally finish the data record of both WTS values and respondents' personal information.

In order to make the survey design easy to understand, the simple valuate target of a tree will be used as an example here. A typical question in WTP considers how much a respondent would pay to protect the tree or to improve its condition. A typical question in WTA considers tree ownership and how much its owner, the respondent would accept if the tree is cut down. Here are explanation principles about describing the survey questions when conducting WTS (see Figure 5); the key point of WTS survey question design is to keep respondents in a neutral position. If the question is described as the respondent may have a closer relationship with the sell-side, it would likely lead to an overestimated value; contrarily, if the question is asked as the respondent standing closer to the purchaser, respondent would likely to prefer a cost-effective price. Same psychological distance from both sell-side and purchaser is very important because it makes the respondent a neutral third-party, and removes them from personal loss and benefit consideration. Some common operational situations of WTS surveys are listed as the Table 1 shows below, and if other CVM research applies WTS in various general valuation surveys; WTS question design will be greatly enriched in the future.

Compared with WTP, an important value in WTS is called Willingness to Depreciate (WTD), which represents deterioration in environmental conditions and how much depreciation occurs in the willingness to sell value. Although they use the same economic model, WTS is free from external factors like income level in WTP. Figure 6 indicates the foundation of WT$\mathrm{D}$ through the indifference curve of utility but with no external factors. If WTD techniques are undertaken well the results are more objective than WTP in theory. In this research, the WTD theory is built and mentioned, the survey techniques of WTD have not been undertaken extensively but we believe that, the combinatorial questions with WTD can be used in WTS questions during field survey designs to make the data more accurate and specific.

Table 1. Possible Situations of WTS Question Describing

\begin{tabular}{lll}
\hline $\begin{array}{l}\text { Example } \\
\text { target: a tree }\end{array}$ & Possible situations & Questions \\
\hline & $\begin{array}{l}\text { Respondent's friend A wa- } \\
\text { nts to sell the tree to respo- }\end{array}$ & What price may be rea- \\
ndent's another friend B & friend A and B?
\end{tabular}

\section{Preliminary Test in Field Survey: A Case-Control Study by Using "How Much Can be Sold" Questions}

\subsection{Valuation Object, Survey Design and Sample}

The CVM application in this research is conducted in Amoy island (Figure 7), which located in Amoy City, Fujian province in Southeast China. The city area comprises $1573.16 \mathrm{~km}^{2}$; average temperature is 18.5 to $25.4^{\circ} \mathrm{C}$ in 2014 ; annual precipitation is $1663.1 \mathrm{~mm}$ in 2014 ; resident population is $3,730,000$ 
in 2013 (XMBS, 2015). Amoy city was selected due to the following reasons: 1) Amoy city pays high attention to city planning and Strategy Environment Assessment. 2) Amoy city is famous for its tourist resources and holds national fame as a livable city with good weather and natural environment. 3) Amoy city implements many general government projects and new planning, with excellent plan publicity; and local government pays attention to public participation. Therefore, Amoy is considered to be a suitable field survey site for CVM application.

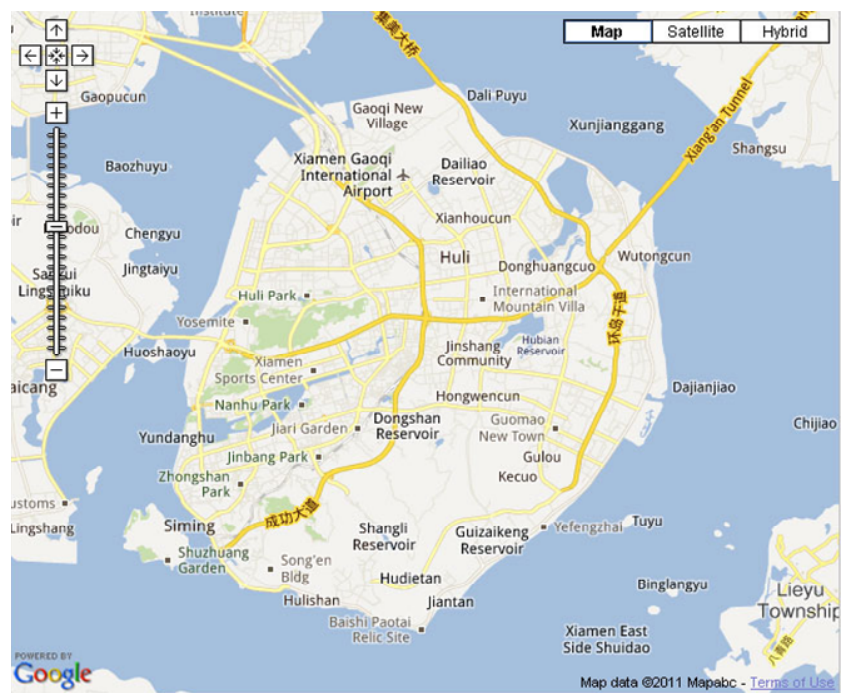

Figure 7. Map of Amoy Island (Source: Google).

Table 2. Details of the Circular Road

\begin{tabular}{ll}
\hline Coastline length & $43 \mathrm{~km}$ \\
Coastline width & 44 to $60 \mathrm{~km}$ \\
Motor drive path & 18 to $24 \mathrm{~m}$ \\
Bike path & 6 to $7 \mathrm{~m}$ \\
Walking path & 6 to $8 \mathrm{~m}$ \\
Full length of tourism resource & $39 \mathrm{~km}$ \\
Green belt & 80 to $100 \mathrm{~m}$ \\
Total area of green & 47 ha \\
History investment & $¥ 3,800,000,000$ \\
\hline
\end{tabular}

Table 3. Outline of the Interview Survey

\begin{tabular}{lll}
\hline \multirow{2}{*}{ Period } & Amoy Circular Road & Amoy Bay Park \\
\cline { 2 - 3 } $\begin{array}{l}\text { No. of } \\
\text { samples }\end{array}$ & 38 (Male: 22; Female: & 31 (Male: 19; Female: 12 ) \\
Method & $\begin{array}{l}\text { Directly interview by researcher around Amoy Circu- } \\
\text { lar Road and inside Amoy Bay Park } \\
\text { Sample }\end{array}$ & $\begin{array}{l}\text { Quota sampling (sex, age) and convenience sampling } \\
\text { combined }\end{array}$ \\
\hline
\end{tabular}

Amoy Circular Road green road improvement project (XMPC, 2012) is selected as an experimental target project and Amoy Bay Park is selected as a control group project in this field survey. Amoy Circular Road is a road by the sea around Amoy Island whose green width is over 50 meters. It is an urban traffic road, tourism resource and an urban green area at the same time. Table 2 shows the details of the Circular Road. From 2012, the government set a new goal to make the Circular Road an international tourism coastline, and until now many different kinds of small projects are undertaken every year; such as (1) part rectification projects; (2) facilities upgrade; (3) new landscaping projects. For these reasons and on the basis of public information available from the XMPC, a green road part improvement project was chosen and the planning scheme (including planning chart) is available from the website of the government. In addition, Amoy Bay Park is chosen as the casecontrol reference project because it has a similar economic level in planning with the Amoy Circular Road green road renovate project, and the investment in Bay Park is $¥ 170,000,000$. The researcher had knowledge of this value and respondents were not told the economic value of the Bay Park.

In the field survey, a respondent self-administered survey has been avoided. An Interview survey is chosen as the investigation method and the investigator directly questioned the respondents after explaining the research and survey purpose. It took about 10 to 20 minutes per respondent to finish the survey. Planning details including many pictures were printed and the investigator showed these and gave verbal guidance until the respondents understood the CVM method and the whole project, and finally asked them to answer the questions. Non-probability sampling was chosen using quota sampling (sex, age) as well as convenience sampling combined method in undertaking the interview survey and all the data was recorded by the investigator. Table 3 shows the outline information of the interview survey.

\subsection{Interview Process and CVM Questions}

Two surveys were conducted under the same environmenttal conditions through the same survey process. The following is the content of the Amoy Circular Road survey: A printed detailed explanation of Amoy Circular Road green-way improvement project with pictures was shown to the respondents first and then continues verbal instructions about the importance of public participation in the planning process. After make sure they have had a full understanding of the project, CVM questions are asked in the following order: from WTP question, WTS question, to WTA question.

1. WTP question: If the construction of the new project requires public donations, how much money are you willing to donate for the project at most?

2. WTS question: If this greenway open space belongs to one of your friends now, for some reasons he wants to sell the open space to your another friend, as a middle man, how much money do you think it would be worth? What price do you think may be reasonable for both buyer and seller?

3. WTA question: If this greenway open space belongs to you and if this greenway is going to be demolished for other land use purposes and you can not enjoy here anymore, suppose you can receive some financial compensation and how much money will you ask for compensation at the least?

In addition, for Amoy Bay Park, the process was almost 
the same, a printed detail of Amoy Bay Park with pictures was shown to the respondents first and then CVM questions were asked in the same order. Detailed questions as follows:

1. WTP question: If a new construction of a new park like Amoy Bay Park requires public donations, how much money are you willing to donate for the new park at most?

2. WTS question: If this Amoy Bay Park belongs to one of your friends now, for some reasons he wants to sell the park to your another friend, as a middle man, how much money do you think it would be worth? What price do you think may be reasonable for both buyer and seller?

3. WTA question: If this Amoy Bay Park belongs to you and if this park is going to be demolished for other land use purposes and you can not enjoy here in the future, suppose you can receive some financial compensation and how much money will you ask for compensation at the least?

Of course, since it was a direct face-to-face investigation, the presentation of the questions of each respondent's was not exactly the same way, but the core is in accordance with the list of the above questions.

Table 4. Number of Samples in Every Survey

\begin{tabular}{|c|c|c|c|c|c|c|c|c|}
\hline \multirow{2}{*}{ Age } & \multicolumn{3}{|c|}{ Amoy Circular Road } & \multirow[b]{2}{*}{$\%$} & \multicolumn{3}{|c|}{ Amoy Bay Park } & \multirow[b]{2}{*}{$\%$} \\
\hline & Female & Male & Total & & Female & Male & Total & \\
\hline $10-19$ & 2 & 0 & 2 & 5.3 & 2 & 1 & 3 & 9.7 \\
\hline $20-2$ & 10 & 11 & 21 & 55.3 & 6 & 9 & 15 & 48.4 \\
\hline $30-39$ & 2 & 9 & 11 & 28.9 & 3 & 3 & 6 & 19.3 \\
\hline $40-49$ & 2 & 2 & 4 & 10.5 & 1 & 6 & 7 & 22.6 \\
\hline Total & 16 & 22 & 38 & 100 & 12 & 19 & 31 & 100 \\
\hline & $42.1 \%$ & $57.9 \%$ & $100 \%$ & & $38.7 \%$ & $61.3 \%$ & $100 \%$ & \\
\hline
\end{tabular}

Table 5. Frequency of Visits to Amoy Circular Road per Year

\begin{tabular}{lll}
\hline Frequency of visit & No. of samples & Percentage (\%) \\
\hline Less than 5 times/year & 16 & 42.1 \\
5 to 10 times/year & 4 & 10.5 \\
10 to 20 times/year & 6 & 15.8 \\
Over 20 times/year & 12 & 31.6 \\
& 38 & 100 \\
\hline
\end{tabular}

Table 6. Frequency of Visits to Amoy Bay Park per Year

\begin{tabular}{lll}
\hline Frequency of visit & No. of samples & Percentage (\%) \\
\hline Less than 5 times/year & 12 & 38.7 \\
5 to 10 times/year & 10 & 32.3 \\
10 to 20 times/year & 9 & 29.0 \\
Over 20 times/year & 0 & 0 \\
& 31 & 100 \\
\hline
\end{tabular}

Table 7. Importance and Satisfaction of Amoy Circular Road

\begin{tabular}{llllll}
\hline \multirow{2}{*}{ Satisfaction } & \multicolumn{2}{l}{ Importance of Amoy Circular Road } \\
\cline { 2 - 5 } & $\begin{array}{l}\text { Extremely } \\
\text { important }\end{array}$ & $\begin{array}{l}\text { Generally } \\
\text { important }\end{array}$ & $\begin{array}{l}\text { Not } \\
\text { important }\end{array}$ & Total \% \\
\hline Very satisfied & 9 & 0 & 0 & 9 & 23.7 \\
Generally & 26 & 1 & 0 & 27 & 71.1 \\
satisfied & 2 & 0 & 0 & 2 & 5.2 \\
Not satisfied & 2 & 1 & 0 & 38 & 100 \\
Total & 37 & 2.6 & 0 & 100 & \\
$\%$ & 97.4 & & & &
\end{tabular}

\subsection{Questions about Personal Details}

After CVM questions, total 11 aspects of the personal details of the respondents have been recorded at the end of the field survey in this research, 1) Local Amoy citizen or not; 2) Access frequency; 3) Purpose of visit; 4) Visit companion; 5) Importance of the target place; 6) Satisfaction of the target place; 7) Age; 8) Gender; 9) Employment; 10) Education level; and 11) Income level.

Table 8. Number of Samples in Every Survey

\begin{tabular}{llllll}
\hline \multirow{2}{*}{ Satisfaction } & \multicolumn{3}{l}{ Importance of Amoy Circular Road } & & \multicolumn{2}{l}{$\begin{array}{l}\text { Extremely } \\
\text { important }\end{array}$} & $\begin{array}{l}\text { Generally } \\
\text { important }\end{array}$ & $\begin{array}{l}\text { Not } \\
\text { important }\end{array}$ & \multicolumn{2}{c}{ Total \% } \\
\hline Very satisfied & 12 & 2 & 0 & 14 & 45.2 \\
Generally & 11 & 4 & 0 & 15 & 48.4 \\
satisfied & & 1 & 0 & 2 & 6.4 \\
Not satisfied & 1 & 7 & 0 & 31 & 100 \\
Total & 24 & 22.6 & 0 & 100 & \\
$\%$ & 77.4 & & & &
\end{tabular}

Table 9. Descriptive Statistics for the Amoy Circular Road

\begin{tabular}{llllll}
\hline Chinese Yuan & $\mathrm{N}$ & Minimum & Maximum & Mean & Sdv \\
\hline WTP & 38 & 0 & $3.00 \mathrm{E} 3$ & $3.93 \mathrm{E} 2$ & $5.98 \mathrm{E} 2$ \\
WTS & 38 & $5.00 \mathrm{E} 5$ & $3.00 \mathrm{E} 9$ & $2.77 \mathrm{E} 8$ & $5.69 \mathrm{E} 8$ \\
WTA & 38 & $1.50 \mathrm{E} 6$ & $5.00 \mathrm{E} 10$ & $2.09 \mathrm{E} 9$ & $8.10 \mathrm{E} 9$ \\
Valid N (listwise) & 38 & & & & \\
\hline
\end{tabular}

Table 10. Descriptive Statistics for the Amoy Bay Park

\begin{tabular}{llllll}
\hline Chinese Yuan & $\mathrm{N}$ & Minimum & Maximum & Mean & Sdv \\
\hline WTP & 31 & $5.00 \mathrm{E} 1$ & $1.00 \mathrm{E} 3$ & $1.31 \mathrm{E} 2$ & $2.41 \mathrm{E} 2$ \\
WTS & 31 & $5.00 \mathrm{E} 5$ & $1.00 \mathrm{E} 9$ & $1.04 \mathrm{E} 8$ & $1.92 \mathrm{E} 8$ \\
WTA & 31 & $1.00 \mathrm{E} 6$ & $2.00 \mathrm{E} 9$ & $4.28 \mathrm{E} 8$ & $4.89 \mathrm{E} 8$ \\
Valid N (listwise) & 31 & & & & \\
\hline
\end{tabular}

\subsection{Results and Discussion}

Table 4 shows number of respondents by gender and age bracket. Unfortunately, in this investigation, no respondent over the age of 50 has been interviewed.

Tables 5 and 6 show the frequency of visits to the survey site. The frequency of Amoy Circular Road shows an interesting pattern that respondents tend to separate the two extremes; frequency less than 5 times per year and over 20 times per year have taken the majority and occupy $73.7 \%$ in total.

Tables 7 and 8 show number of respondents by importance and satisfaction bracket of Amoy Circular Road and Amoy Bay Park. The majority of respondents show extremely importance of both as $97.4 \%$ and $77.4 \%$ and satisfaction of survey area is relatively high.

\subsection{Values of WTP, WTS and WTA}

Table 9 shows the descriptive statistics value of WTP, WTS and WTA of Circular Road and Table 10 represents the values for Bay Park. The Amoy Construction Department determined the economic investment value of Amoy Bay Park at about 170,000,000 Chinese Yuan, and after checking the WTP, WTS and WTA values of Amoy Bay Park; we were pleasantly 
surprised to find that the WTS value $103,580,645.16$ is the closest value to the real economic investment, and since the process of the filed survey was strictly controlled by researchers and we did not give the respondents any suggestive inform of the real value. The actual amount of investment of Bay Park is the government's internal data, did not open to the public.

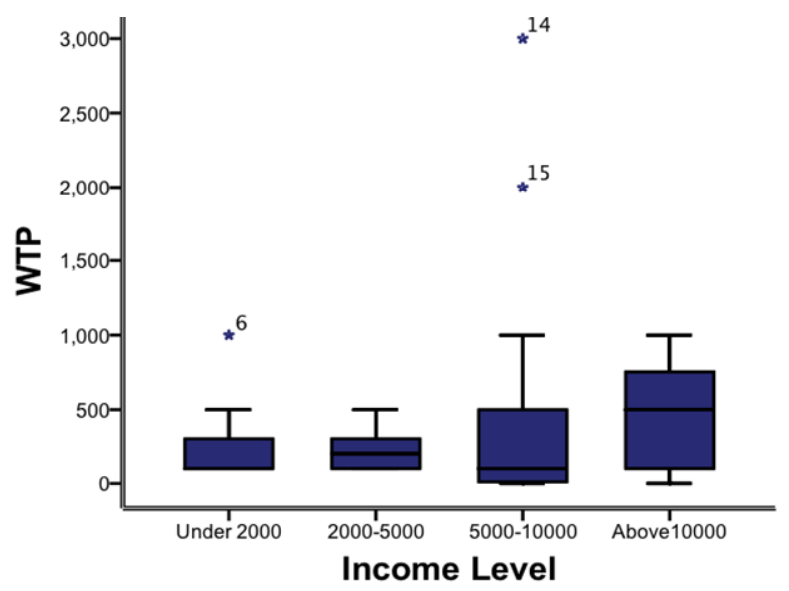

Figure 8. Circular road WTP \& income level.

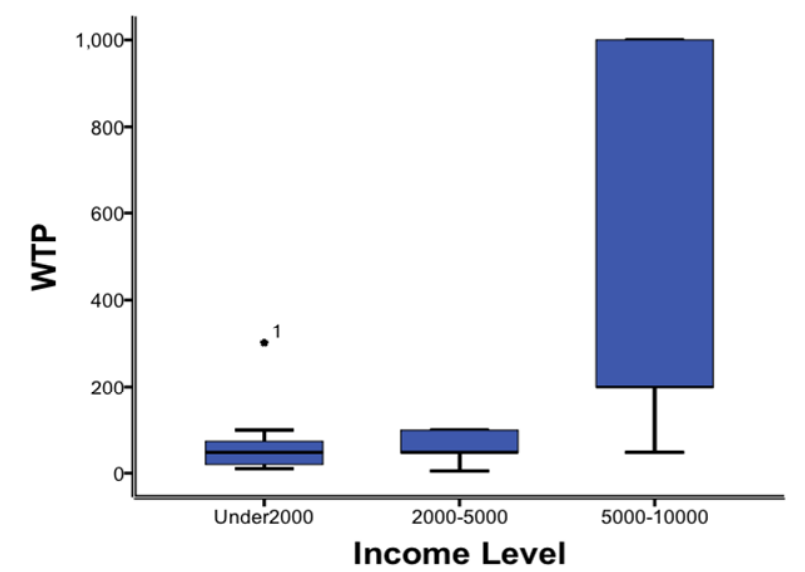

Figure 9. Bay park WTP \& income level.

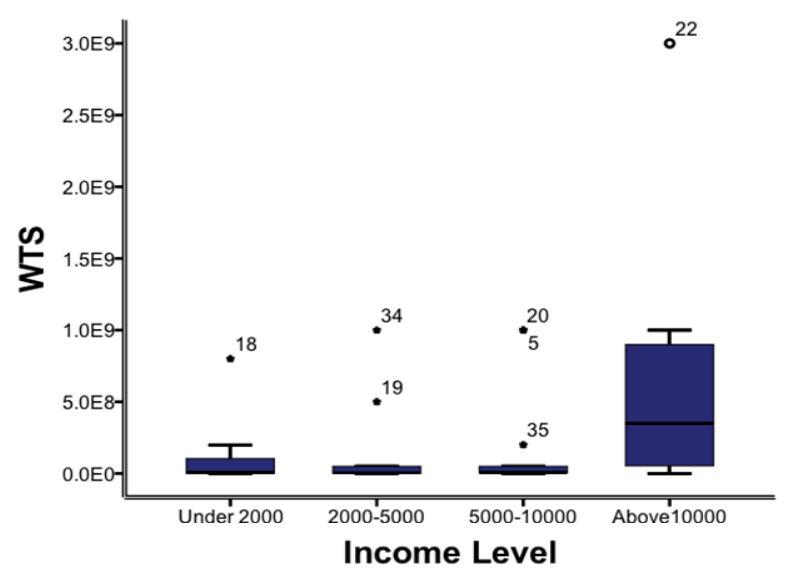

Figure 10. Circular road WTS \& income level.
Table 11. Exploration of Respondents' Thinking Mode

\begin{tabular}{|c|c|c|c|}
\hline $\begin{array}{l}\text { Question } \\
\text { type }\end{array}$ & Reaction of respondents & $\begin{array}{l}\text { No. of } \\
\text { samples }\end{array}$ & $\%$ \\
\hline \multirow{6}{*}{ WTP } & Personal income level & 62 & 89.9 \\
\hline & It is depended on my income & 28 & 40.6 \\
\hline & If I have more, I will donate more & 21 & 30.5 \\
\hline & I really want to contribute to this & & \\
\hline & $\begin{array}{l}\text { new project but I have a poor } \\
\text { income }\end{array}$ & 13 & 18.8 \\
\hline & Others & 7 & 10.1 \\
\hline \multirow{5}{*}{ WTS } & Real market as reference & 68 & 98.6 \\
\hline & I want to know the land price & 41 & 59.4 \\
\hline & $\begin{array}{l}\text { I need a little time to think about } \\
\text { the price of my house for } \\
\text { reference }\end{array}$ & 21 & 30.5 \\
\hline & $\begin{array}{l}\text { It's depended on the market } \\
\text { conditions and deferent years } \\
\text { sometime }\end{array}$ & 6 & 8.7 \\
\hline & Others & 1 & 1.4 \\
\hline \multirow{5}{*}{ WTA } & $\begin{array}{l}\text { Subjective feelings and } \\
\text { imagination }\end{array}$ & 69 & 100 \\
\hline & I don't want it to be broken at all & 18 & 26.2 \\
\hline & $\begin{array}{l}\text { I refuse to accept any } \\
\text { compensation conditions }\end{array}$ & 7 & 10.1 \\
\hline & May I imagine to say & 31 & 44.9 \\
\hline & $\begin{array}{l}\text { I don't know how much money I } \\
\text { really want }\end{array}$ & 13 & 18.8 \\
\hline
\end{tabular}

\subsection{Correlation Analyses and Thinking Mode Analysis}

An important correlation analysis is about income level and the WTP value of both Circular Road (Figure 8) and Bay Park (Figure 9) show extremely clearly that WTP has a positive correlation with personal income level. Thus, people who have a higher income level are more likely to pay more for the environment or public services. While the relationship between $\mathrm{W}$ TS value and income level is not clear. In the Circular Road WTS \& Income figure (Figure 10), the highest WTS value of each income level is almost the same, in other words, people can value public service through an 'how much can be sold' question and this kind of WTS thinking can be considered independent of income level. Bay Park WTS \& Income figure (Figure 11) also shows an almost equal WTS value for the different income levels. It is important to note the Figure 10 and it is obvious that the respondents with an income above 10,000 Chinese Yuan are likely to highly value the environment. But the WTS values do not have an clear incremental relationship with income level in the overall shape; only respondents with an income of over 10,000 Chinese Yuan consider the environment worth more. The highest WTA value of the Circular Road (Figure 12) for each income level is almost the same and it is likely it has no obvious positive relationship with income level. However, the figures for the Bay Park WTA \& Income (Figure 13) indicate the WTA value for income under 2000 Chinese Yuan is much higher than the others. In other words, in the Bay Park case, people with poor income level are more likely to claim more compensation.

An analysis of respondents' thinking model has been explored as the Table 11 shows. When considering WTP questions, 
about $89.9 \%$ of respondents considered their personal income level for the first time; when considering WTA questions, 100\% answered the questions just on the basis of their own subjective feelings and imagination; and when they considered the WTS questions, about $98.6 \%$ tried to consider the real market as a reference in their mind.

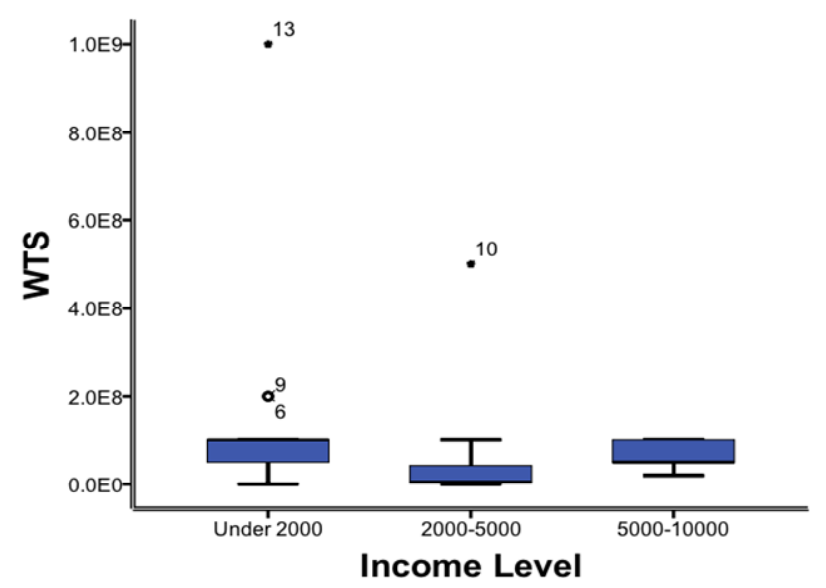

Figure 11. Bay park WTS \& income level.

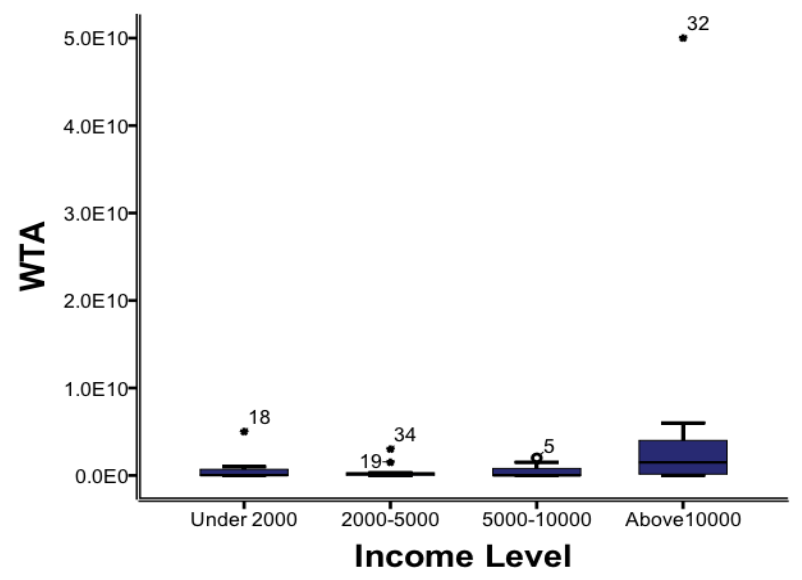

Figure 12. Circular road WTA \& income level.

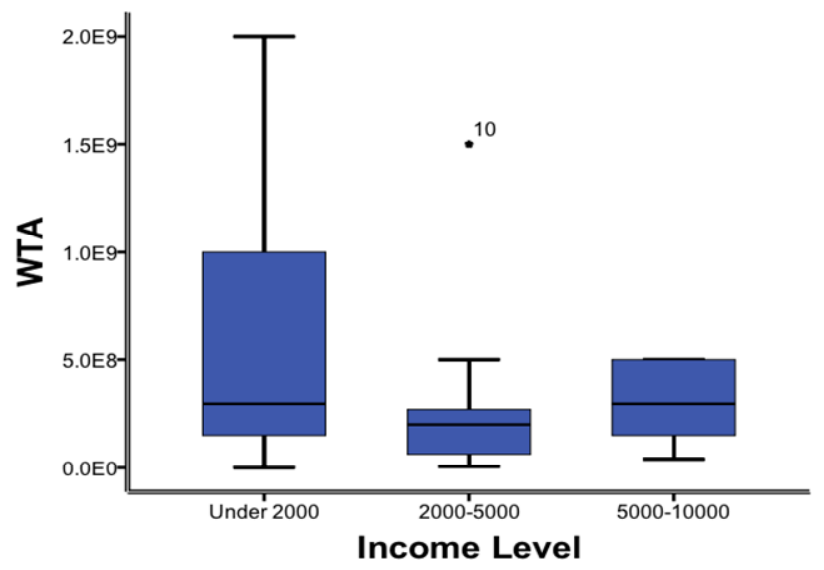

Figure 13. Bay park WTA \& income level.

\subsection{Discussion of the Field Survey}

In the preliminary test, since the number of respondents is very limited and the huge target project has not been separated, and only asked the most basic questions, the specific numerical deviation possibility is great, but we can still get some trends from the survey analysis. During the field survey, the respondents showed resistance to answering WTP questions and were happy to answer WTS questions compared with WTP questions. Besides, the final value of WTS is much closer to the real market unlike the huge bias of WTA and the too-low valuation of WTP (Besides, since it is difficult to delineate the appropriate population size, the total WTP value is unclear); it can provide an advisable support on the investment of purchase public goods or the investment of the whole public project. Although all social surveys more or less depend on the personal characteristics of respondents', WTS is greatly free from the influence of many external factors such as income level compared with WTP. While, WTS techniques also have some limits, such as WTS is better to valuate those small-scale projects, or small public goods because public respondents sometimes have no idea about very huge and expensive projects. To overcome this problem, the investigator needed to be experienced to explain every detail of the large project to the respondent and finish the separating work before going to field survey. More 'how much can be sold' questions should be designed which is suitable for questionnaire surveys in the future work.

\section{Discussion}

Considering the ecosystem service project to be valuated, some testing questions in the field survey showed that the respondents hold resistance to answering WTP questions and felt relaxed to answer WTS questions compared with WTP questions. Besides, the final value of WTS can be much more objecttive and closer to the real market if it can be well conducted; it can provide an advisable support on the investment of purchasing public goods or the investment of providing ecosystem services. Although all social surveys more or less depend on the personal characteristics of respondents, WTS technique is considered not so strong related to the influence of some external factors compared with WTP such as the influence of income level.

While in order to reduce the bias, the investigator is required to be experienced and explain every detail of the large project to the respondent during WTS survey process, because WTS technique is more likely to be a reasonable appraisal process and a comprehensive three-dimensional cognition of the target is extremely necessary. In addition, the investigator must respect respondents' concept of the market and avoid unreasonable interference and inducing.

\section{Future Work}

Extensive studies have documented the importance of the understanding of the economic value of ecosystem services and it provides an important reference for the government planning decisions. Considered some influences of external factors du- 
ring the process of WTP surveys, better systematic models need to be created to quantify the economic value of ecosystem services as important as the experiences of specific application cases. Recently, there have been a number of WTP applications in more extensive field especially for different kinds of ecosystem services. Through different fields of research and application of more comprehensive skills combined, the validity of CV$\mathrm{M}$ will also be greatly improved and it is able to provide better data support for local decisions. More applications and improvement of the valuation system will be expected in the future work, and the systematic models of valuating ecological services will be gradually summarized with more generality. In the future research, we will pay more attention on the separation of the target project and enrich the design of specific experimental program and survey questions; and we hope we can finish more comparisons between WTP and WTS data through different field survey in different area and countries.

\section{Conclusions}

The economic valuation method of ecosystem services is getting abundant through applications in different fields. In this research, WTS theory has been built on the basis of the combination of environmental science and economics. We discussed and resolved the issues of theoretical construction, mathematical modeling, implementation of the process, and survey method and question designs in this research, and we also discussed the advantages and points to be improved about WTS techniques compared with WTP and WTA through the filed survey testing. When considering WTS questions, respondents will try to consider the economy market as a reference on the basis of their common sense of the real market. This kind of thinking mode is even more important than a detailed value, thus, a methodology can ask the respondents to value the target on the basis of using the real market as a reference and this kind of thinking makes WTS value more objective, because the value they give does not greatly depend on their individual preferences for the target to be valuated. WTS is considered to have a very wide scope of application, and is suitable to valuate ecosystem services, public services, public goods, environmental resources and tourism resources. In addition to the more objectivity, WTS has other more convenient advantages, as it is not necessary for $\mathrm{W}$ TS to decide the population range to be calculated.

When undertaking a city planning and Strategy Environment Assessment, government is paying more attention to public opinion before providing ecosystem services recently, and the economic value of the eco-service is expected to be more objective and reliable, and much closer to a reasonable economic investment. The WTS valuation model provides a new method to combine existing ecological and economic models to address this need and we believe that the CVM method will also be greatly enriched with the combination of WTS and existing WTP and WTA.

Acknowledgments. We are very grateful to all the editors and experts in environmental economics for providing valuable comments for this research.

\section{References}

XMBS (2015). Xiamen Special Economic Zone Yearbook, Xiamen Municipal Bureau of Statistics, Xiamen, China.

XMPC (2012). Greenway Planning in Fujian Province (2012-2020), Xiamen Municipal Planning Commission, Xiamen, China.

Carson, R.T., Flores, N.E., and Meade, N.F. (2001). Contingent valuation: controversies and evidence. Environ. Resour. Econ., 19(2), 173-210. https://doi.org/10.1023/A:1011128332243

Dewsbury, B.M., Bhat, M., and Fourqurean, J.W. (2016). A review of seagrass economic valuations: Gaps and progress in valuation approaches. Ecosyst. Serv., 18, 68-77. https://doi.org/10.1016/j.eco ser.2016.02.010

Fowler Jr, F.J. (2008). Survey Research Methods, SAGE Publications. George, A.L., and Bennett, A. (2005). Case Studies and Theory Development in the Social Sciences, MIT press.

Hakim, C. (1987). Research Design, Routledge.

Kuriyama (2000). The Solution of Environmental Assessment and Environmental Accounting(in Japanese), Japan review.

Mitchell, R.C., and Carson R.T. (2013). Using Surveys to Value Public Goods: the Contingent Valuation Method, Resources for the Future, Washington DC, USA.

Portney, P.R. (1994). The contingent valuation debate: why economists should care. J. Econ. Perspect., 8(4), 3-17. https://doi.org/10.1257/ jep.8.4.3

Rea, L.M., and Parker, R.A. (2012). Designing and Conducting Survey Research: A Comprehensive Guide.

Shogren, J.F., Shin, S.Y., Hayes, D.J., and Kliebenstein, J.B. (1994). Resolving differences in willingness to pay and willingness to accept. Am. Econ. Rev., 84(1), 255-270.

Yin, R.K., and Heald, K.A. (1975). Using the case survey method to analyze policy studies. Admin. Sci. Q., 20(3), 371-381. https://doi. org/10.2307/2391997

Yin, R.K. (2013). Case Study Research: Design and Methods, Sage publications.

Yoshino, K., Setiawan, B.I., and Furuya, H. (2010). Economic Valuation for Cidanau Watershed Area, Indonesia. J. Trop. For. Manage., 16(1), 27-35. 